\title{
Kisspeptin Levels in Girls with Precocious Puberty: A Systematic Review and Meta-Analysis
}

\author{
Rafael Guerra Cintra ${ }^{a}$ b Rubens Wajnsztejn ${ }^{b}$ Camila Martins Trevisan ${ }^{a}$ \\ Victor Zaia ${ }^{a}$ Antonio Simone Laganà ${ }^{c}$ Bianca Bianco $^{d}$ Erik Montagna $^{a}$ \\ aPostgraduate Program in Health Sciences, Faculdade de Medicina do ABC/Centro Universitário Saúde ABC, \\ Santo André, Brazil; bepartment of Neurosciences, Discipline of Neurology, Faculdade de Medicina do \\ $A B C / C e n t r o$ Universitário Saúde ABC, Santo André, Brazil; 'Department of Obstetrics and Gynecology, \\ "Filippo Del Ponte" Hospital, University of Insubria, Varese, Italy; ${ }^{d}$ Department of Collective Health, Discipline of \\ Sexual and Reproductive Health and Populational Genetics, Faculdade de Medicina do ABC/Centro Universitário \\ Saúde ABC, Santo André, Brazil
}

\section{Keywords}

Central precocious puberty · Kisspeptin · Gonadotropinreleasing hormone $\cdot$ Biomarker

\begin{abstract}
Background/Aims: Kisspeptin (KP) is a key player in the regulation of the release of gonadotropin-releasing hormone $(\mathrm{GnRH})$, which increases the secretion of gonadotropin during puberty to establish reproductive function and regulate the hypothalamic-pituitary-gonadal axis. Premature activation of GnRH secretion leads to idiopathic/central gonadotropin-dependent precocious puberty (CPP). We aimed to compare the blood KP concentrations in girls with CPP and healthy controls. Methods: A systematic review and metaanalysis was performed. We searched MEDLINE, EMBASE, The Cochrane Library, and SciELO. Random-effects model and standardized mean difference (SMD) were used. Heterogeneity was assessed through $R^{2}$. Meta-regression considered patient age, KP fraction, and analytical method for KP measurement. Results: The 11 studies included comprised 316 CPP patients and 251 controls. Higher KP levels in the
\end{abstract}

karger@karger.com

(c) 2021 S. Karger AG, Basel

www.karger.com/hrp

Karger"
CPP group were found (SMD 1.53; Cl 95\% $=0.56-2.51$ ). Subgroup analysis revealed association with patient age $(p=$ 0.048 ), indicating a positive correlation between elevation in $\mathrm{KP}$ concentration and age in CPP group. A group of patients with precocious thelarche (PT) from 5 of the included studies comprising 121 patients showed higher levels of KP (1.10; $-0.25-2.45: \mathrm{Cl} 95 \%)$ and high heterogeneity $\left(I^{2}=91 \%\right)$. The CPP/PT ratio for KP level indicates KP 36\% higher on CPP than PT patients. Conclusions: A consistent difference in KP levels between girls with CPP and controls was identified. While there are important limitations in KP assays which argue against its use as a diagnostic tool, the KP levels in CPP versus control and PT children are consistent with the predicted mechanisms and pathophysiology of CPP.

(c) 2021 S. Karger AG, Basel

\section{Introduction}

Puberty represents a complex biological process of sexual development which leads the individual to attain secondary sexual characteristics and reproductive capac- 
ity [1]. Pubertal development results from an increase in impulses and frequency of gonadotropin-releasing hormone $(\mathrm{GnRH})$ from the hypothalamus, which is coordinated by a mechanism involving inhibitory, stimulatory, and permissive factors acting upstream of GnRH neurons [2]. This mechanism is determined by a complex interaction of metabolic, environmental, nutritional, ethnic, and genetic factors [1], although it is far from being fully elucidated. Clinically, the onset of puberty is defined as the first appearance of breast buds in girls, whereas in boys the first pubertal sign is the testicular enlargement. Generally, it occurs between the ages of 8-13 in girls and 9-14 in boys [3].

Precocious puberty is defined as the development of puberty younger than that which is expected for ethnicity and race $[4,5]$. Premature activation of GnRH secretion leads to idiopathic gonadotropin-dependent precocious puberty (or CPP) [6].

One of the key players in the initiation of puberty is the kisspeptin (KP), a family of neuropeptides encoded by the KISS1 gene, mapped at 1q32. KPs act through the binding and subsequent activation of the $\mathrm{G}$ protein-coupled receptor, KISS1R, which is encoded by the KISS1R gene, mapped at 19p13.3 [7-9]. KPs act on GnRH neurons increasing the secretion of gonadotropin - luteinizing hormone (LH) and follicular stimulating hormone (FSH) during puberty; as KP levels increase, the amplitude and frequency of $\mathrm{GnRH}$ pulsatility is augmented [10-12]. The action of LH and FSH on the gonads also stimulates the production of sex steroids, gametogenesis, sexual maturation, and provides hormonal feedback loops that regulate the release of $\mathrm{GnRH}, \mathrm{LH}$, and FSH [13]. Additionally, hypothalamic expression of KISS1/KISS1R increases during the puberty in rats and monkeys [14]. Activating and inactivating mutations in KISS1 or KISS1R genes cause pubertal failure and precocious puberty in children [1517]. Concentrations of hypothalamic KP were causally associated with $\mathrm{GnRH}$ activation and reproductive maturation in humans $[9,18-21]$. Prevalence of CPP has been predicted to be $0.2 \%$ in general population [22], and interestingly, females are at least 10 times more likely to develop premature puberty than males $[6,23]$.

Cases of CPP are particularly interesting to investigate, as uncovering the underlying defect may lead to better understanding of yet unknown or understudied pathways critical for puberty. Furthermore, KP is considered a novel biochemical marker of pubertal activation that may help to diagnose and/or manage children with pubertal disorder, for which many studies have been proposed. Even though, there are no comparative studies that examined the magnitude of circulating concentrations of $\mathrm{KP}$ in children with precocious puberty. Considering this, we performed a systematic review and meta-analysis aiming to compare the concentrations of blood KP in girls with precocious puberty and controls.

\section{Material and Methods}

\section{Search Strategy}

A systematic review and meta-analysis was registered in PROSPERO (CRD: 42020147473) and developed according to the Preferred Reporting Items for Systematic Reviews and Meta-Analyses (PRISMA) statement [24]. We searched the electronic databases MEDLINE, EMBASE, the Cochrane Library, and SciELO. The search strategy included only terms relating to or describing the main features, adapted for each bibliographic database ("kisspeptin" OR "metastin”) AND ("precocious puberty") and correlate terms in order to obtain the largest number of articles involving KP dosage. The search included articles in any language from the inception of the abovementioned databases to April 2020.

\section{Selection of Studies}

Titles and/or abstracts of studies retrieved were independently screened by 2 review authors. The full text was retrieved and independently assessed for eligibility by 3 reviewers, with disagreements resolved through discussion with an external collaborator. We have included studies enrolling girls diagnosed with CPP confirmed by Tunner criteria for pubertal development, or breast bud started before the age of 8 , or LH and FSH baseline/peak levels, or bone age analysis that were compared with a healthy control group and that performed blood KP dosage.

The exclusion criteria were CPP caused by neurological disorders such as tumors, trauma, malformations, or genetic syndromes. We also excluded incomplete report or pooled data without the possibility of data extraction for subgroups, reviews, casereports, animal models, in vitro, or in silico studies.

\section{Data Extraction}

A standardized form was used for data extraction, assessment, and evidence synthesis by 3 authors independently, with discrepancies resolved through discussion. Missing data were requested to authors when needed.

The primary data retrieved were the first author, publication year, sample sizes, and KP concentrations for case and control groups. Secondary information included age, body mass index, diagnostic criteria for CPP, KP fraction identified, pre-analytical, and analytical procedures, and kit manufacturer. KP serum concentrations were converted to $\mathrm{pmol} / \mathrm{mL}^{-1}$ in order to provide the number of active molecules per volumetric unity. We considered the molar mass of the KP fraction according to the PubChem Compound Database (National Center for Biotechnology Information). Measures reported were transformed to mean and standard deviation if reported otherwise according to previous studies [25].

\section{Risk of Bias Assessment}

We used a modified version of the Newcastle-Ottawa Scale (NOS) [26] in order to include parameters which could interfere with KP measurement. It was considered the patient selection cri- 
Fig. 1. Flow diagram of study selection. SciELO, scientific electronic library online; $\mathrm{KP}$, kisspeptin

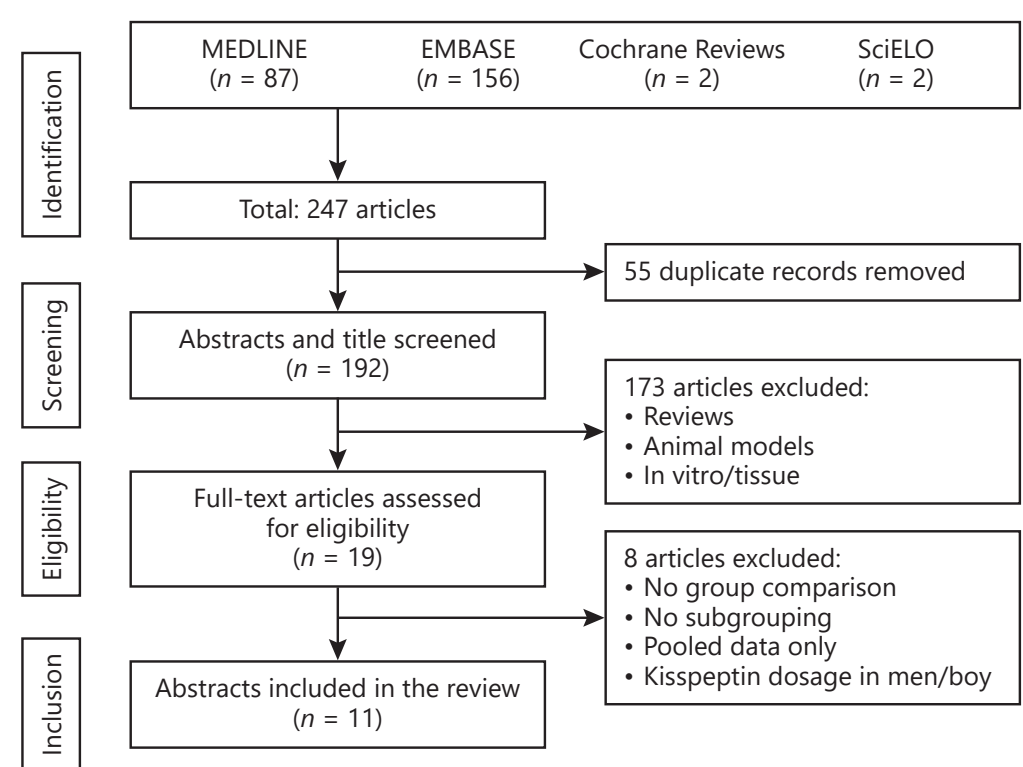

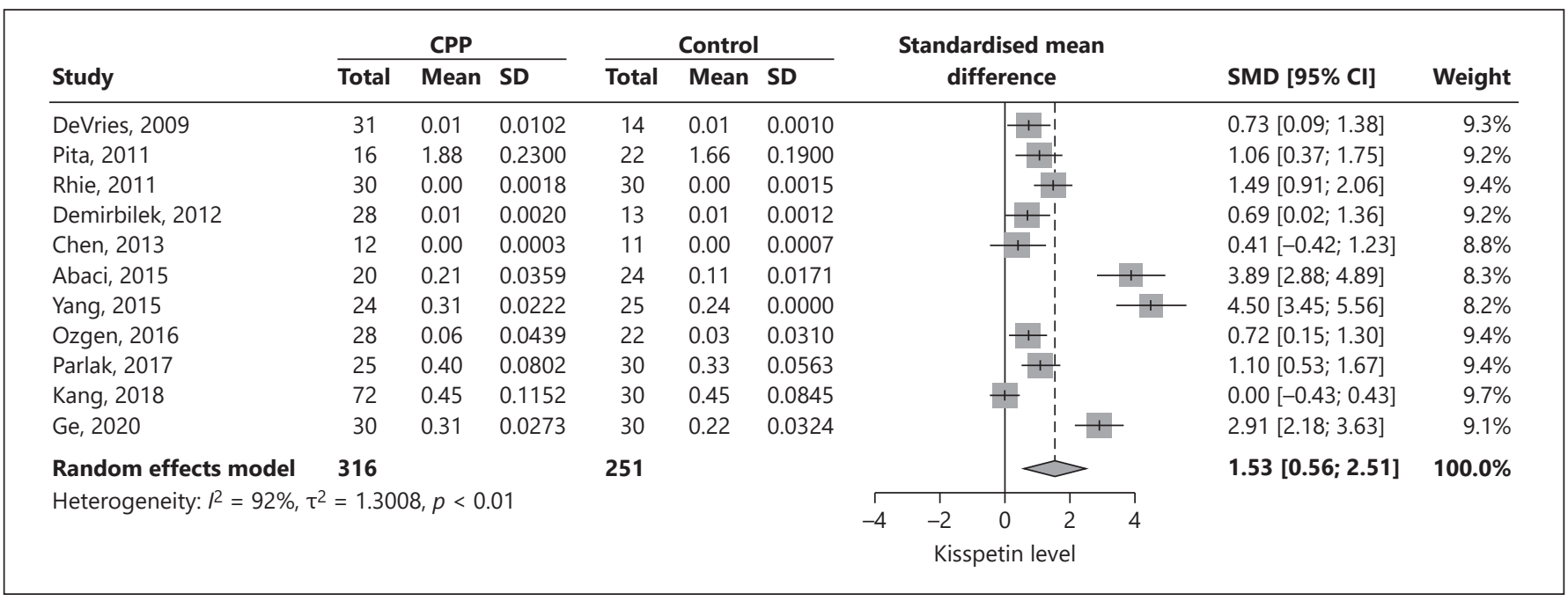

Fig. 2. Forest plot of KP levels in patients with CPP versus healthy controls. KP, kisspeptin; CPP, central gonadotropin-dependent precocious puberty; SD, standard deviation; SMD, standardized mean difference

teria presented in the original articles, the description of data collection and timeframe between the data collection and patients' CPP diagnostic. Pre-analytical parameters consider the description of the sample treatment before analysis, description of tube for sample collection (e.g., EDTA or protease inhibitor), time lapse between the sample collection and processing, sample temperature maintenance until processing, processing protocol (e.g., centrifugation, separation, and fraction obtained), and protein purification techniques for KP fraction isolation. Analytical parameter comprises technique (e.g., Enzyme-Linked Immunosorbent Assay [ELISA] or radioimmunoassay [RIA]), dosage protocol, parameters (calibration curve, sensitivity, and ROC curve), and interfer- ents. Three authors assessed the studies considering low, medium, or high risk of bias, with discrepancies resolved through discussion.

\section{Statistical Analysis}

The meta-analysis was performed using a random-effect model. The bias-corrected standardized mean difference (SMD) was adopted [27] for pooling estimates due to the large variations in the KP concentrations observed in the studies. Heterogeneity was tested with $\tau^{2}$ and $I^{2}$ statistics [28], considering values between 50 and $75 \%$ moderate, and high if $>75 \%$. In addition, a meta-analysis of studies which also presented precocious thelarche (PT) com- 


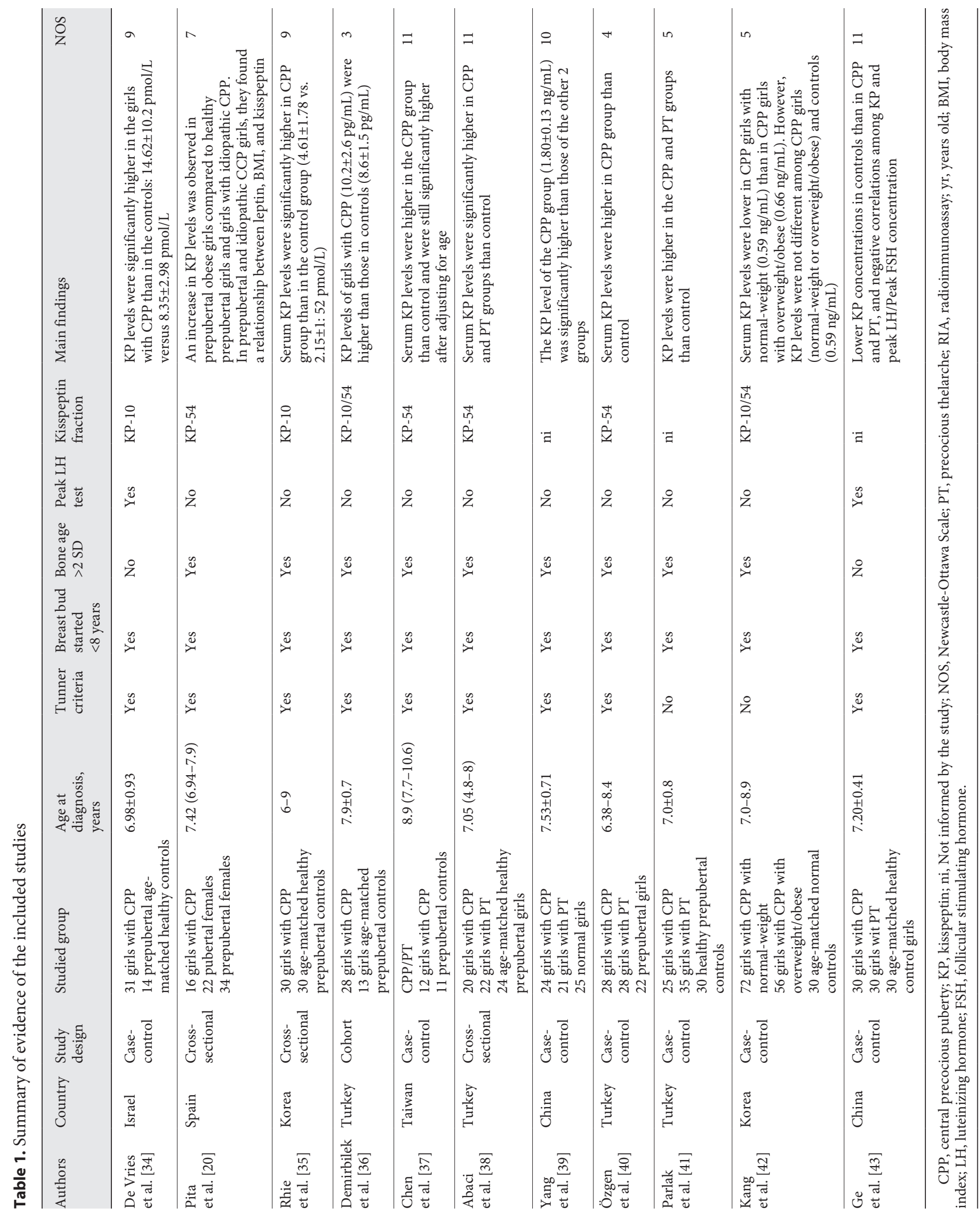



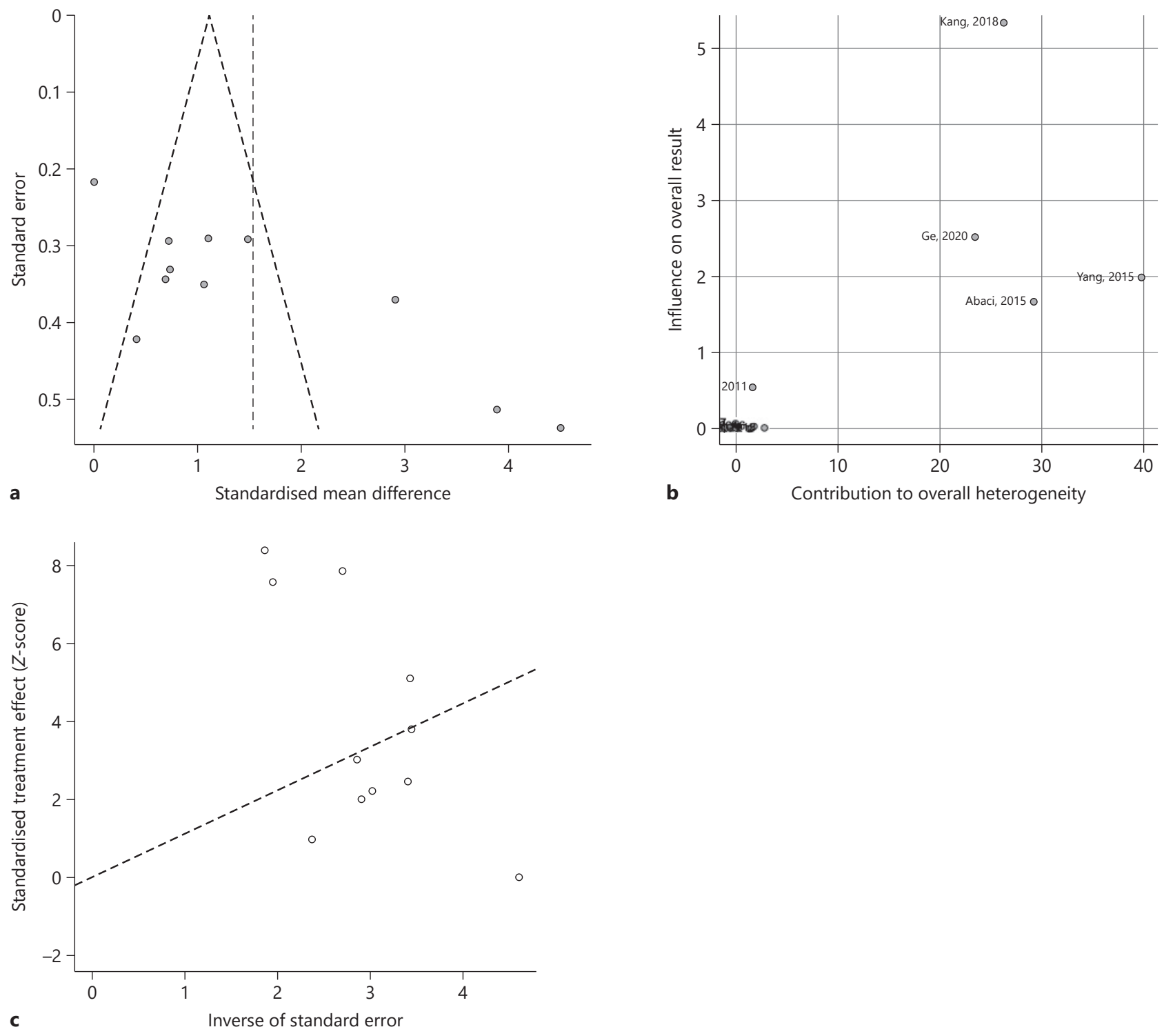

Fig. 3. Analysis of publication bias. Publication bias is presented as funnel plots considering the SMD (a), as a Baujat plot considering the publication bias and general contribution of each study (b), and the radial plot (c). The Baujat plot shows the contribution of each study to the overall Q-test statistic for heterogeneity. SMD, standardized mean difference

pared to $\mathrm{CPP}$ was performed, and the KP level related to patient age as previously reported [29]. The Egger test [30], the Baujat plot [31], and the radial plot [27] were used to detect sources of heterogeneity. Results are displayed as forest plots showing SMD and 95\% CIs.

Meta-regression analysis was conducted with mixed-effects model and the DerSimonian-Laird estimator. Parameters tested were patient age, disease staging, and analytical procedures when possible. The results of the meta-regression analysis are given as re- gression coefficients with 95\% CIs. Post hoc analyses for patients with PT were considered after data extraction for subgroup analysis.

Data imputation was performed when the KP fraction was not described. We checked the manufacturer reported in the methods section, and if unavailable, we assumed that the KP fraction used was the KP-54 considering that commercial kits commonly use such fraction. Statistical analyses were performed with RStudio (version 1.1.383), using the meta [32] and the metafor packages [33]. 


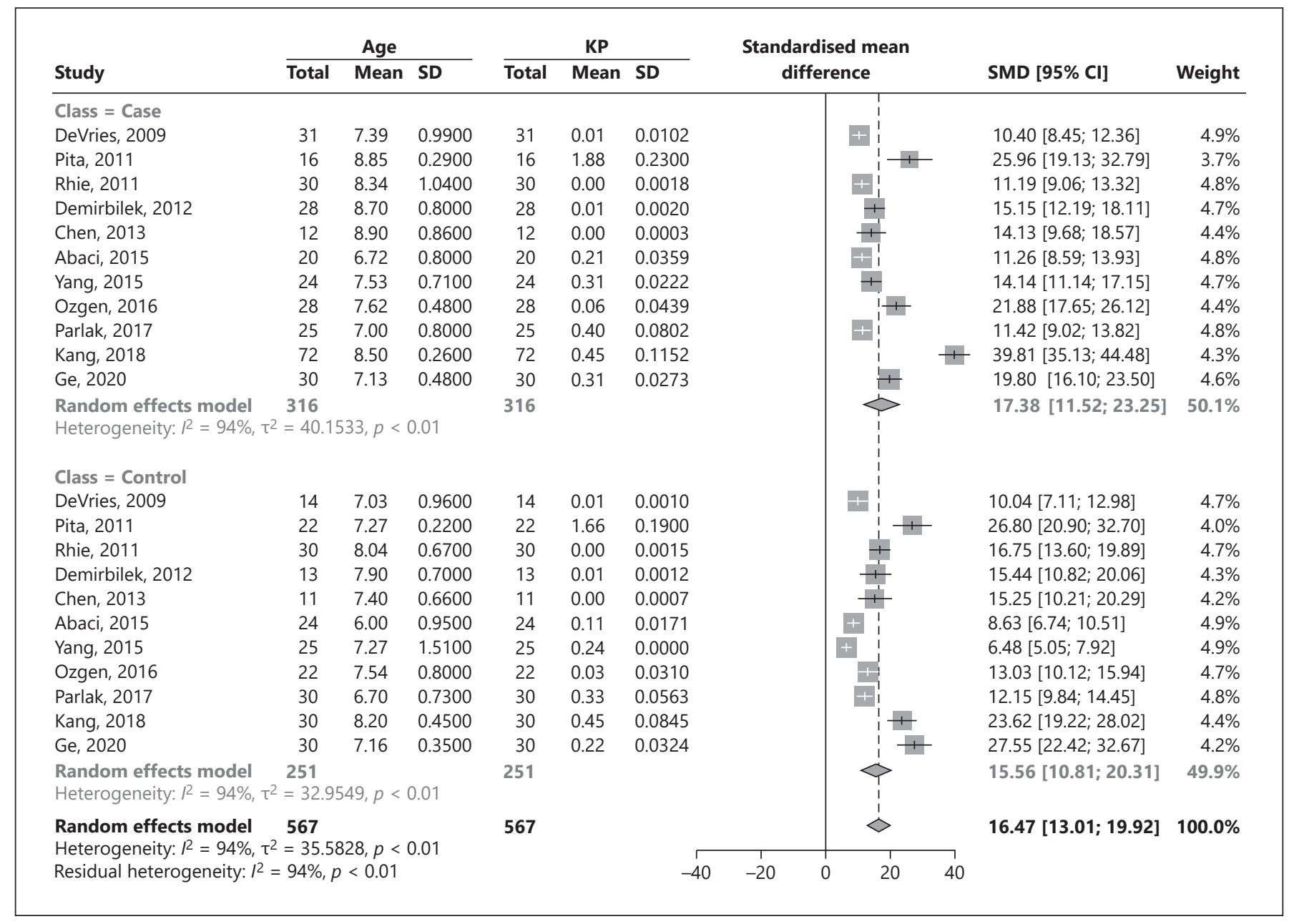

Fig. 4. Forest plot of patient age versus KP levels for CPP and control groups. KP, kisspeptin; CPP, central gonadotropin-dependent precocious puberty; SD, standard deviation; SMD, standardized mean difference

\section{Findings}

Systematic Review and Summary of Evidence

A total of 11 studies [20,34-43] were included, comprising 316 CPP patients and 251 controls. Figure 1 outlines study selection process in a PRISMA flowchart. The summary of evidence is presented in Table 1.

\section{Results of the Meta-Analyses}

The Kisspeptin levels were higher in the CPP group than the control group $(\mathrm{SMD}=1.53$; CI 95\% $=0.56-2.51$ ). The heterogeneity was $I^{2}=92 \%$, considered high (Fig. 2).

\section{Risk of Bias}

Figure $3 \mathrm{a}, \mathrm{b}$, and c present the funnel plot, Baujat plot, and radial plot, respectively. The linear regression test of the funnel plot reveals asymmetry $(p=0.004)$. The Baujat plot confirms that the 3 studies [38, 39, 43] were strong sources of heterogeneity.

\section{Quality Assessment}

The NOS scale presented variations among the studies (see online suppl. Table 1; for all online suppl. material, see www.karger.com/doi/10.1159/000515660). Four studies presented high risk of bias [19, 36, 40, 41], and the remaining varied from mild [20] to low risk. Studies showed poor descriptions of the sample collection and pre-analytical procedures. The description of the healthy controls presented mixed results with 5 studies presenting limited descriptions [20, 34, 36, 40, 41]. However, the case group characteristics, description, and diagnostic criteria presented generally better descriptions. 


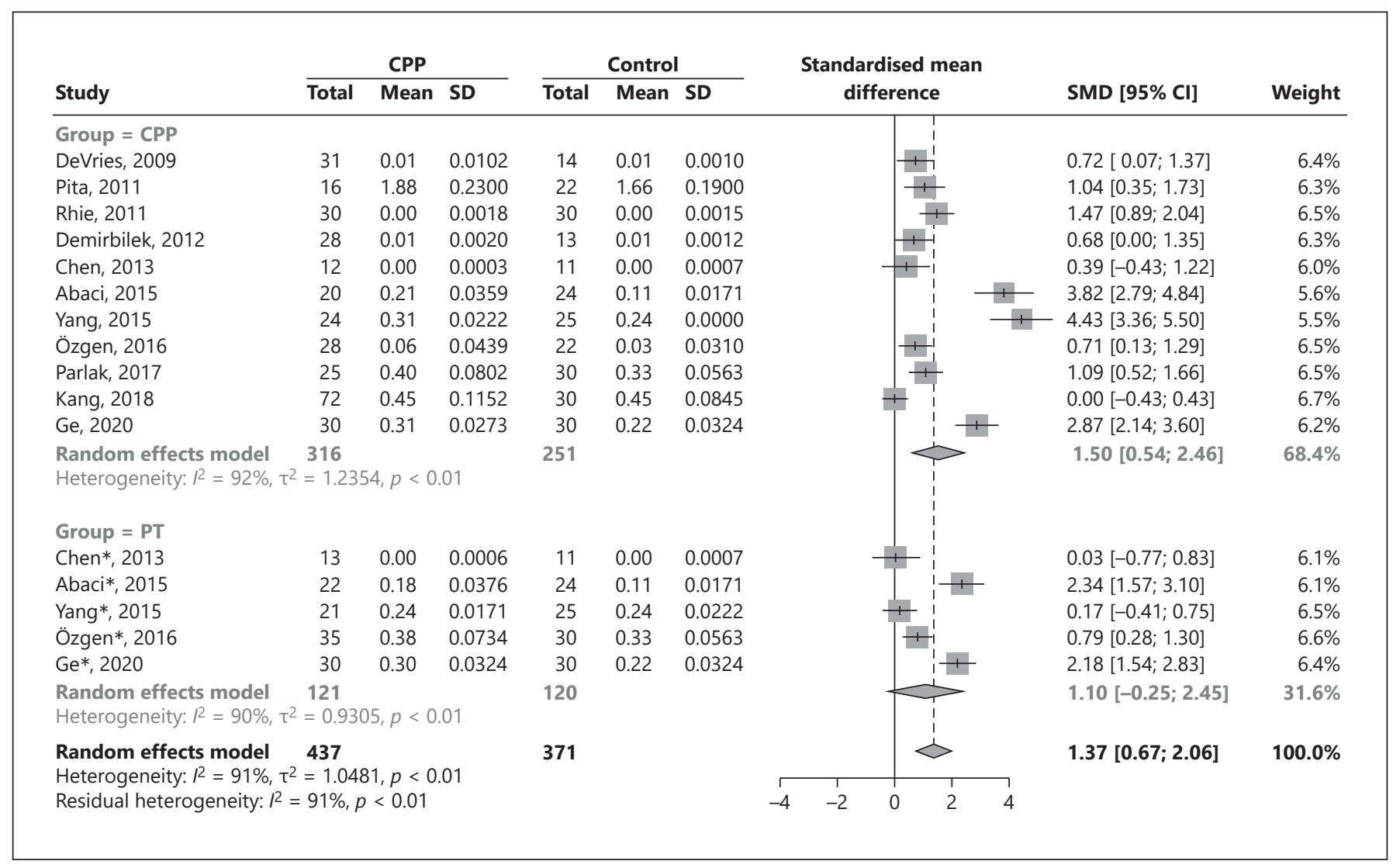

Fig. 5. Forest plot of subgroup analysis comparing CPP and PT patients from studies. CPP, central gonadotropindependent precocious puberty; SD, standard deviation; SMD, standardized mean difference; PT, precocious thelarche

\section{Subgroup Analysis}

Meta-regression tests considered analytical techniques (ELISA vs. RIA), KP fraction (KP-54 vs. KP-10), and patient age (case vs. control groups). No significant contribution of analytical technique ( $p=0.1728)$ or the KP fraction used $(p=0.2415)$ was observed. However, it was significant for the age of patients $(p=0.048)$, with a residual heterogeneity of $R^{2}=21.91 \%$. This finding indicates a positive correlation between the elevation in KP concentration and age in the CPP group. In this sense, 2 forest plots were produced in order to obtain further details about the aspects relevant to age and disease progression (Fig. 4, 5).

The first subgroup analysis consisted of a withingroup evaluation of the relationship between patient age and KP levels (Fig. 4). The meta-analysis was performed comparing age versus KP levels in CPP group and age versus KP levels in control group. The result for each comparison allows the estimation of the difference of $\mathrm{KP}$ level between the groups by the standpoint of the patient age. The result of age versus $\mathrm{KP}$ in the case group (CPP patients) was 17.38 (11.52-23.25; 95\% CI) comprising $50.1 \%$ of the weighted sample and for the control group was 15.56 (10.81-20.31; 95\% CI) comprising $49.9 \%$ of the weighted sample. The age versus KP for the case/control ratio estimate was 1.12 and indicates a KP level approximately $12 \%$ higher on CPP patients regardless of the age differences among the groups and studies.

The second subgroup analysis was performed comparing CPP patients versus control group with PT patients versus the control group (Fig. 5). The analysis of PT patients included data from 5 of the included studies [37,38, $39,40,43$ ] comprising 121 patients with PT and 120 patients in the control group, respectively, also with higher levels of KP in the PT group (1.10; $-0.25-2.45$ : CI 95\%) and high heterogeneity $\left(I^{2}=91 \%\right)$. The $\mathrm{CPP} / \mathrm{PT}$ ratio for $\mathrm{KP}$ level is 1.36 and indicates a KP level approximately $36 \%$ higher on CPP patients than PT patients. 


\section{Discussion}

The exact cause of puberty initiation is still poorly understood $[44,45]$ and approximately $90 \%$ of girls with CPP have an idiopathic cause [46]. KP has been identified as one of the key players to pubertal initiation [5, 47]. KISS1 encodes a 138-amino-acid peptide precursor of $\mathrm{KP}$, which is proteolytically processed into a 54 -aminoacid protein, and can be further cleaved to 14,13 , and 10 amino-acid peptides widely referred to as "kisspeptins." KPs have recently been identified as vital upstream regulators that integrate both central and peripheral signals with GnRH release [9]. Evidences have shown that systemic or central administration of KP in immature female rats and in a gonadal juvenile male monkeys induced precocious activation of the gonadotropic axis, by provoking $\mathrm{GnRH}$ secretion from hypothalamic GnRH neurons expressing KISS1R [48, 49]. It was showed that KP levels are higher in girls with CPP than in age-matched healthy prepubertal girls [23] and also suggested that this parameter may be useful as an adjunctive tool in the diagnosis of the CPP [34].

Using a systematic review and meta-analysis, we compared the KP levels between 316 girls with CPP and 251 controls from 11 studies (Table 1) [20,34-43]. In all studies, the values of KP concentration were higher in CPP girls than in controls (SMD $=1.53$; CI 95\% $=0.56-2.51$ ), except in 1 study [42] which found no difference in KP levels. However, the presence of an overlap between KP levels of girls with CPP and the control group suggests that KP levels alone cannot be strong criteria for CPP diagnosis.

There is a comparative paucity of data examining the circulating concentrations of KP during human reproductive development. This is mainly attributable to the technical challenge of measuring plasma KP in blood samples. Rapid centrifugation and separation are required in order to avoid substantial degradation of KP in the blood samples [50]. Regarding the adoption of preanalytical procedures to improve KP detection, 4 articles reported the use of tubes with protease inhibitor to prevent $\mathrm{KP}$ degradation $[20,34,39,43]$ and 1 reported the use of protein purification column [35]. However, this observation alone does not explain the differences observed in the KP concentration. Moreover, some analytical factors were different among the studies, despite the fact that meta-regression revealed that KP fraction measured (KP-54 vs. KP-10), and the analytical procedure (ELISA or RIA) did not significantly contribute to the heterogeneity observed. Three studies presented even higher difference for KP concentration between the case and controls $[38,39,43]$ than the other studies. However, no common characteristics were observed to explain such differences.

On the other hand, the meta-regression analysis showed positive correlation between the patient age and KP concentration. These data indicate that the KP levels rise with patient age in $\mathrm{CPP}$, although the KP level was approximately $12 \%$ higher on CPP patients regardless of the age differences among the groups and studies. Activation of GnRH neurons is the key to triggering the initiation of the puberty as KP neurons are connected to $\mathrm{GnRH}$ neurons. Studies in animal models and humans showed that the central or peripheral administration of KP was able to induce precocious activation of the gonadotropic axis and precocious pubertal development, besides to exert a potent stimulatory effect on gonadotropins secretion [21, 51-55].

In addition to age, the subgroup analysis showed an association between KP levels and PT. The levels of KP in PT group were above the observed in healthy patients and below the observed in CPP patients. PT is defined as the isolated breast development without the development of other sexual characteristics [56], often occurs in toddler girls, and usually regresses over several months [23]. The possible causes of PT include increased FSH secretion, but not LH, excessive dietary intake of estrogens and phytoestrogens, obesity, and endocrine-disrupting chemicals $[57,58]$. Therefore, early breast development is not always manifestations of CPP. The differential diagnosis between the early stages of CPP and PT is challenging and requires clinical and laboratory investigation, with longterm follow-up.

As puberty is metabolically gated, obesity has been shown to impact the timing of puberty [59]. KP has a close relationship with leptin, suggesting a link between the metabolism and reproduction $[42,60,61]$. There is evidence for changes in central KP expression both in response to food restriction (negative energy balance) or in genetic or diet-induced models of obesity (positive energy balance), without firm consensus [46].

The limitations of the present study rely on the high heterogeneity, the quality of clinical data provided in the articles, and the huge variation in KP levels observed even after the normalization of concentration unity. In addition, possible variants in the KISS1 and KISS1R genes that could interfere in the KP levels were not evaluated. Also, the technical challenges of KP assays are evident in the studies reviewed. Finally, our study is based on observational studies, which are more subject to biases. 


\section{Conclusion}

To the best of our knowledge, this is the first metaanalysis to compare KP levels in girls with CPP and controls, showing consistently higher levels in CPP patients. The meta-regression indicated that the KP levels are positively correlated with patient age. Also, the level of $\mathrm{KP}$ is higher in CPP than in PT. These findings are coherent with the pathophysiology of the condition. Finally, important limitations in KP dosage strongly advise against its use as a regular diagnostic tool even in face of its undeniable value as a biomarker in this complex scenario.

\section{Acknowledgments}

The authors would like to thank Nicole Paloma de Assis Rodrigues for the support in the selection of the studies.

\section{Statement of Ethics}

The research was conducted and developed according to the PRISMA statement. This systematic review and meta-analysis was registered in PROSPERO (CRD: 42020147473). A study approval statement was not required for this study type; no human or animal subjects were used.

\section{Conflict of Interest Statement}

The authors have no conflicts of interest to declare.

\section{Funding Sources}

The authors did not receive any funding.

\section{Author Contributions}

R.G.C., B.B., and E.M. conceived the study. B.B. and E.M. designed the research. R.G.C., C.M.T., V.Z., and E.M. extracted the data. All the authors analyzed the data. R.G.C., B.B., and E.M. wrote the manuscript. All the authors critically reviewed the manuscript and approved the final version of the manuscript.

\section{Availability of Data and Materials}

The datasets used in this study are available from the corresponding author on reasonable request.

\section{References}

1 Latronico AC, Brito VN, Carel JC. Causes, diagnosis, and treatment of central precocious puberty. Lancet Diabetes Endocrinol. 2016; 4(3):265-74.

2 Macedo DB, Silveira LF, Bessa DS, Brito VN, Latronico AC. Sexual precocity-genetic bases of central precocious puberty and autonomous gonadal activation. Endocr Dev. 2016; 29:50-71.

3 Roelants M, Hauspie R, Hoppenbrouwers K. References for growth and pubertal development from birth to 21 years in Flanders, Belgium. Ann Hum Biol. 2009;36(6):68094.

4 Fuqua JS. Treatment and outcomes of precocious puberty: an update. J Clin Endocrinol Metab. 2013;98(6):2198.

5 Aguirre RS, Eugster EA. Central precocious puberty: from genetics to treatment. Best Pract Res Clin Endocrinol Metab. 2018;32(4): 343-54.

6 Bianco SD. A potential mechanism for the sexual dimorphism in the onset of puberty and incidence of idiopathic central precocious puberty in children: sex-specific kisspeptin as an integrator of puberty signals. Front Endocrinol. 2012;3:149.

7 Kotani M, Detheux M, Vandenbogaerde A, Communi D, Vanderwinden JM, Le Poul E, et al. The metastasis suppressor gene KISS-1 encodes kisspeptins, the natural ligands of the orphan G protein-coupled receptor GPR54. J Biol Chem. 2001;276(37):34631-6.

8 Ohtaki T, Shintani Y, Honda S, Matsumoto $\mathrm{H}$, Hori A, Kanehashi K, et al. Metastasis suppressor gene KiSS- 1 encodes peptide ligand of a G-protein-coupled receptor. Nature. 2001; 411(6837):613-7.

9 Trevisan CM, Montagna E, de Oliveira R, Christofolini DM, Barbosa CP, Crandall KA, et al. Kisspeptin/GPR54 system: what do we know about its role in human reproduction? Cell Physiol Biochem. 2018;49(4): 1259-76.

10 de Roux N, Genin E, Carel JC, Matsuda F, Chaussain JL, Milgrom E. Hypogonadotropic hypogonadism due to loss of function of the KiSS1-derived peptide receptor GPR54. Proc Natl Acad Sci USA. 2003;100(19): 10972-6.

11 Seminara SB, Messager S, Chatzidaki EE, Thresher RR, Acierno JS Jr, Shagoury JK, et al. The GPR54 gene as a regulator of puberty. N Engl J Med. 2003;349(17):1614-27.

12 Harms JF, Welch DR, Miele ME. KISS1 metastasis suppression and emergent pathways. Clin Exp Metastasis. 2003;20(1):11-8.

13 Simoni M, Nieschlag E. FSH in therapy: physiological basis, new preparations and clinical use. Reprod Med Rev. 1995;4(3):163-77.
14 Roa J, Navarro VM, Tena-Sempere M. Kisspeptins in reproductive biology: consensus knowledge and recent developments. Biol Reprod. 2011;85(4):650-60.

15 Seminara SB. Metastin and its G protein-coupled receptor, GPR54: critical pathway modulating GnRH secretion. Front Neuroendocrinol. 2005;26(3-4):131-8.

16 Bianco SD, Vandepas L, Correa-Medina M, Gereben B, Mukherjee A, Kuohung W, et al. KISS1R intracellular trafficking and degradation: effect of the Arg386Pro disease-associated mutation. Endocrinology. 2011;152(4) 1616-26.

17 Jayasena CN, Nijher GM, Narayanaswamy S, De Silva A, Abbara A, Ghatei MA, et al. Agedependent elevations in plasma kisspeptin are observed in boys and girls when compared with adults. Ann Clin Biochem. 2014;51(Pt 1): 89-96.

18 Rehman R, Fatima SS, Alam F, Ashraf M, Zafar S. Kisspeptin and attributes of infertile males and females: a cross-sectional study in a subset of Pakistani population. Andrologia. 2019;51(9):e13370.

19 Kaya A, Orbak Z, Polat H, Çayır A, Erdil A, Döneray $\mathrm{H}$. Plasma kisspeptin levels in newborn infants with breast enlargement. J Clin Res Pediatr Endocrinol. 2015;7(3): 192-6. 
20 Pita J, Barrios V, Gavela-Pérez T, MartosMoreno GÁ, Muñoz-Calvo MT, Pozo J, et al. Circulating kisspeptin levels exhibit sexual dimorphism in adults, are increased in obese prepubertal girls and do not suffer modifications in girls with idiopathic central precocious puberty. Peptides. 2011;32(9):1781-6.

21 Jayasena CN, Abbara A, Veldhuis JD, Comninos AN, Ratnasabapathy R, De Silva A, et al. Increasing LH pulsatility in women with hypothalamic amenorrhoea using intravenous infusion of kisspeptin-54. J Clin Endocrinol Metab. 2014;99(6):E953-61.

22 Teilmann G, Pedersen CB, Jensen TK, Skakkebaek NE, Juul A. Prevalence and incidence of precocious pubertal development in Denmark: an epidemiologic study based on national registries. Pediatrics. 2005;116(6):1323-8.

23 de Vries L, Guz-Mark A, Lazar L, Reches A, Phillip M. Premature thelarche: age at presentation aff ects clinical course but not clinical characteristics or risk to progress to precocious puberty. J. Pediatr.. 2010;156:466-71.

24 Moher D, Shamseer L, Clarke M, Ghersi D, Liberati A, Petticrew M, et al. Preferred reporting items for systematic review and metaanalysis protocols (PRISMA-P) 2015 statement. Syst Rev. 2015;4(1):1.

25 Hozo SP, Djulbegovic B, Hozo I. Estimating the mean and variance from the median, range, and the size of a sample. BMC Med Res Methodol. 2005;5:13.

26 Modesti PA, Reboldi G, Cappuccio FP, Agyemang C, Remuzzi G, Rapi S, et al. ESH working group on CV risk in low resource settings. Panethnic differences in blood pressure in Europe: a systematic review and meta-analysis. PLoS One. 2016;11:e0147601.

27 Borenstein M. Introduction to meta-analysis. Chichester, UK: John Wiley \& Sons; 2009.

28 Higgins JP, Thompson SG, Deeks JJ, Altman DG. Measuring inconsistency in meta-analyses. BMJ. 2003;327(7414):557-60.

29 de Assis Rodrigues NP, Laganà AS, Zaia V, Vitagliano A, Barbosa CP, de Oliveira O, et al. The role of Kisspeptin levels in polycystic ovary syndrome: a systematic review and meta-analysis. Arch Gynecol Obstet. 2019;300:423-34.

30 Sterne JA, Egger M. Funnel plots for detecting bias in meta-analysis: guidelines on choice of axis. J Clin Epidemiol. 2001;54(10):1046-55.

31 Baujat B, Mahé C, Pignon J-P, Hill C. A graphical method for exploring heterogeneity in meta-analyses: application to a meta-analysis of 65 trials: graphical method for exploring heterogeneity in meta-analyses. Stat. Med.. 2002;21(18):2641-52.

32 Schwarzer G, Carpenter JR, Rücker G. Metaanalysis with R. Cham Heidelberg New York Dordrecht London: Springer; 2015.

33 Viechtbauer W. Conducting meta-analyses in $\mathrm{R}$ with the meta for package. J Stat Soft. 2010; 36(3): 1-48

34 de Vries L, Shtaif B, Phillip M, Gat-Yablonski G. Kisspeptin serum levels in girls with central precocious puberty. Clin Endocrinol. 2009;71(4):524-8.
35 Rhie YJ, Lee KH, Eun SH, Choi BM, Chae HW, Kwon AR, et al. Serum kisspeptin levels in Korean girls with central precocious puberty. J Korean Med Sci. 2011;26(7):927-31.

36 Demirbilek H, Gonc EN, Ozon A, Alikasifoglu A, Kandemir N. Evaluation of serum kisspeptin levels in girls in the diagnosis of central precocious puberty and in the assessment of pubertal suppression. J Pediatr Endocrinol Metab. 2012;25(3-4):313-6.

37 Chen CY, Chou YY, Wu YM, Lin CC, Lin SJ, Lee CC. Phthalates may promote female puberty by increasing kisspeptin activity. Hum Reprod. 2013;28(10):2765-73.

38 Abaci A, Catlı G, Anık A, Küme T, Calan OG, Dündar BN, et al. Significance of serum neurokinin B and kisspeptin levels in the differential diagnosis of premature the larche and idiopathic central precocious puberty. Peptides. 2015;64:29-33.

39 Yang YU, Xiong XY, Yang LI, Xie L, Huang $\mathrm{H}$. Testing of kisspeptin levels in girls with idiopathic central precocious puberty and its significance. Exp Ther Med. 2015;9(6):236973.

40 Özgen İT, Torun E, Bayraktar-Tanyeri B, Durmaz E, Kılıç E, Cesur Y. The relation of urinary bisphenol A with kisspeptin in girls diagnosed with central precocious puberty and premature the larche. J Pediatr Endocrinol Metab. 2016;29(3):337-41.

41 Parlak M, Türkkahraman D, Ellidağ HY, Çelmeli G, Parlak AE, Yılmaz N. Basal serum neurokinin $B$ levels in differentiating idiopathic central precocious puberty from premature the larche. J Clin Res Pediatr Endocrinol. 2017;9(2):101-5.

42 Kang MJ, Oh YJ, Shim YS, Baek JW, Yang S, Hwang IT. The usefulness of circulating levels of leptin, kisspeptin, and neurokinin B in obese girls with precocious puberty. Gynecol Endocrinol. 2018;34(7):627-30.

43 Ge W, Wang HL, Shao HJ, Liu HW, Xu RY. Evaluation of serum makorin ring finger protein 3 (MKRN3) levels in girls with idiopathic central precocious puberty and premature the larche. Physiol Res. 2020;69(1):127-33.

44 Carel JC, Léger J. Clinical practice. Precocious puberty. N Engl J Med. 2008;358(22):236677.

45 Brito VN, Latronico AC, Arnhold IJ, Mendonça $\mathrm{BB}$. Update on the etiology, diagnosis and therapeutic management of sexual precocity. Arq Bras Endocrinol Metabol. 2008; $52(1): 18-31$

46 Wolfe A, Hussain MA. The emerging role(s) for kisspeptin in metabolism in mammals. Front Endocrinol. 2018;9:184.

47 Hussain MA, Song WJ, Wolfe A. There is kisspeptin - and then there is kisspeptin. Trends Endocrinol Metab. 2015;26(10):564-72.

48 Shahab M, Mastronardi C, Seminara SB, Crowley WF, Ojeda SR, Plant TM. Increased hypothalamic GPR54 signaling: a potential mechanism for initiation of puberty in primates. Proc Natl Acad Sci USA. 2005;102(6): 2129-34.
49 Navarro VM, Fernández-Fernández R, Castellano JM, Roa J, Mayen A, Barreiro ML, et al. Advanced vaginal opening and precocious activation of the reproductive axis by KiSS- 1 peptide, the endogenous ligand of GPR54. J Physiol. 2004;561(Pt 2):379-86.

50 Ramachandran R, Patterson M, Murphy KG, Dhillo WS, Patel S, Kazarian A, et al. Preanalytical factors affecting RIA measurement of plasma kisspeptin. Clin Chem. 2008;54(3): 615-7.

51 Owens LA, Abbara A, Lerner A, O'floinn S, Christopoulos G, Khanjani S, et al. The direct and indirect effects of kisspeptin-54 on granulosa lutein cell function. Hum Reprod. 2018; 33(2):292-302.

52 Abbara A, Jayasena CN, Christopoulos G, Narayanaswamy $S$, Izzi-Engbeaya $\mathrm{C}$, Nijher GM, et al. Efficacy of kisspeptin-54 to trigger oocyte maturation in women at high risk of ovarian hyperstimulation syndrome (OHSS) during in vitro fertilization (IVF) therapy. J Clin Endocrinol Metab. 2015;100(9):3322-31.

53 Albers-Wolthers $\mathrm{CH}$, de Gier J, Rutten VP, van Kooten PJ, Leegwater PA, Schaefers-Okkens AC, et al. The effects of kisspeptin agonist canine KP-10 and kisspeptin antagonist p271 on plasma LH concentrations during different stages of the estrous cycle and anestrus in the bitch. Theriogenology. 2016;86(2):589-95.

54 Caraty A, Decourt C, Briant C, Beltramo M. Kisspeptins and the reproductive axis: potential applications to manage reproduction in farm animals. Domest Anim Endocrinol. 2012;43(2):95-102

55 Whitlock BK, Daniel JA, Amelse LL, Tanco VM, Chameroy KA, Schrick FN. Kisspeptin receptor agonist (FTM080) increased plasma concentrations of luteinizing hormone in anestrous ewes. Peer J. 2015;3:e1382.

56 Delemarre-van de Waal HA. Regulation of puberty. Best Pract Res Clin Endocrinol Metab. 2002;16(1):1-12.

57 Rosenfield RL. Normal and almost normal precocious variations in pubertal development. Premature pubarche and premature thelarche revisited. Hormone Res. 1994;41: 7-13.

58 Farello G, Altieri C, Cutini M, Pozzobon G, Verrotti A. Review of the literature on current changes in the timing of pubertal development and the incomplete forms of early puberty. Front Pediatr. 2019;7:147.

59 Sanchez-Garrido MA, Tena-Sempere M. Metabolic control of puberty: roles of leptin and kisspeptins. Horm Behav. 2013;64(2): 187-94.

60 Castellano JM, Navarro VM, FernándezFernández R, Nogueiras R, Tovar S, Roa J, et al. Changes in hypothalamic KiSS-1 system and restoration of pubertal activation of the reproductive axis by kisspeptin in undernutrition. Endocrinology. 2005;146(9):3917-25.

61 Smith JT, Acohido BV, Clifton DK, Steiner RA. KiSS-1 neurones are direct targets for leptin in the ob/ob mouse. J Neuroendocrinol. 2006;18(4):298-303. 